\title{
Mindfulness Based Cognitive Group Therapy vs Cognitive Behavioral Group Therapy as a Treatment for Driving Anger and Aggression in Iranian Taxi Drivers
}

\author{
Toktam Kazemeini ${ }^{*}$, Bahramali Ghanbari-e-Hashem-Abadi, Asieh Safarzadeh \\ Department of Psychology, Ferdowsi University of Mashhad, Mashhad, Iran \\ Email: "Tkazemeini@gmail.com
}

Received November 29 $9^{\text {th }}, 2012$; revised January $6^{\text {th }}, 2013$; accepted July $6^{\text {th }}, 2013$

\begin{abstract}
Copyright (C) 2013 Toktam Kazemeini et al. This is an open access article distributed under the Creative Commons Attribution License, which permits unrestricted use, distribution, and reproduction in any medium, provided the original work is properly cited.
\end{abstract}

\begin{abstract}
The frequent experience of anger while driving is associated with great rates of aggressive and dangerous behaviors. The experience of anger driving can have repercussions that extend beyond the vehicle and can be harmful to the individual driver and other drivers that are in the same road. Thus, the present research aims to compare the effectiveness of Mindfulness Based Cognitive Group Therapy (MBCGT) with Cognitive-Behavior Group Therapy (CBGT) on reducing anger and aggression while driving. The experimental design was pretest, posttest and follow up with randomized assignment. The sample of this study included 20 male taxi drivers who were selected through accessible sampling and participated voluntarily in the research. Participants were randomly divided into two experimental groups. The first experimental group received MBCGT and CBGT was conducted in the second experimental group. Both groups were tested three times (i.e., pretest, posttest, and one-month follow-up). The study tools used were Driving Anger Scale (DAS) and Driving Anger Expression questionnaire (DAX). Data were analyzed using SPSS 16 software with covariance analysis. The results showed that MBCGT in comparison to CBGT led to significant reduction in driving anger, aggressive expression of driving anger and significant increase in adaptive/constructive expression of driving anger. These findings have been discussed theoretically and their importance in clinical importance.
\end{abstract}

Keywords: Mindfulness Based Cognitive Group Therapy; Cognitive-Behavior Group Therapy; Driving Anger and Aggression

\section{Introduction}

Over the past several years interest in angry and aggressive driving behaviors has increased. This interest follows from numerous national and international surveys, which have all shown that driving aggressively and becoming angry while driving is an increasingly frequent and costly phenomenon (AAA Foundation for Traffic Safety, 1997; NHTSA, 1999; Parker, Lajunen, \& Stardling, 1998; Parkinson, 2001; Rasmussen, Knapp, \& Garner, 2000; Underwood, Chapman, Wright, \& Crandall, 1999). So far, researchers have focused a great deal of their attention on trying to define driving anger and aggression, (Ellison-Potter, Bell, \& Deffenbacher, 2001; Hauber, 1980; Novaco, 1990), understanding causative factors for driving anger and aggression (Ellison, Govern, Petri, \& Figler, 1995; Hennessy \& Wiesenthal, 1999; Pinto, 2001; Underwood et al., 1999), the relationship between driving anger and aggression and risky behaviors and their adverse outcomes (Deffenbacher, Huff, Lynch, Oetting, \& Salvatore, 2000; Novaco, Stokols, \& Milanesi, 1990; Malta, Blanchard, Freidenbreg, Galovski, Karl, \& Holzapfel, 2001; Vandervoort, Ragland, \& Syme, 1996). In fact, research has focused even less on treatment for driving anger so that there is a relative void in our knowledge of effec-

\footnotetext{
*Corresponding author.
}

tive interventions for driving anger and aggression (Diebold, 2003). Most of the treatment studies conducted have focused on examining the effectiveness of some techniques of cognitive behavior therapy such as relaxation training, cognitive restructuring, and exposure techniques (Deffenbacher et al., 2000; Deffenbacher, Filetti, Lynch, Dahlen, \& Oetting, 2002; Galovski \& Blanchard, Malta, \& Freidenberg, 2003; Richards, Deffenbacher, Feletti, Lynch, \& Kogan, 2001, Rimm, DeGroot, Boord, Heiman, \& Dillow, 1971). Although the effectiveness of these techniques has been demonstrated using reduction in measures of driving anger and aggression, the results have not shown one intervention to be superior over the others. For example, one study reported that relaxation training techniques showed a reduction on certain measures of driving anger and aggression while the same techniques were not shown to be as effective in another study (Deffenbacher et al., 2000; Deffenbacher et al., 2002). Similar inconsistencies were observed in cognitive restructuring and exposure techniques (Deffenbacher et al., 2002; Galovski \& Blanchard, 2002; Richards et al., 2001). Besides to these partial studies, Galovski and Blanchard (2002) found that a cognitive behavioral treatment helped reduce driving anger and aggression. To a large degree, cognitive behavior therapy is based on the assumption that a reorganization of one's self-statements will result in a corresponding reorganiza- 
tion of one's behavior (Corey, 2009). According to Beck's cognitive view, cognition plays a major role in psychological problems. He believes that other aspects such as emotional, behavioral and physiologic aspects are raised from this one (Ghasemzadeh, 2008). Cognitive change in cognitive-behavior approach emerges in this way that individuals are taught more rational thinking skills and they learn to reject their negative thoughts consciously (Phares, 1992).

On the other hand, there is also direct and indirect evidence in the literature to suggest that mindfulness may be an effective intervention for individuals who experience frequent and intense anger while driving (Borders, 2010; Brown, 2003; Diebold, 2003; Heppner, 2008; Murphy, 1995; Polizzi, 2007; Wright, Andrew, \& Howells, 2009). Mindfulness is an emerging therapeutic technique that combines elements of relaxation with a unique cognitive component. Mindfulness, as conceptualized by researchers such as Kabat-Zin and Buddhist monks like Thich Nhat Hanh, at its most elementary form, is awareness of each moment as it occurs. Based on ancient Buddhist traditions from Asia, mindfulness is not a new technique; however, its systematic application to the treatment of numerous psychological and physical ills is a relatively recent phenomenon (Bishop, 2002). Mindfulness from the outset has been a holistic intervention in the sense that no fundamental distinction is made between body and mind (Rothwel, 2006) and deal with totality of one's existence and personality simultaneously and consider him/her as a integrated whole (Ataee-e-Nakhaei, 2008). Mindfulness Based Cognitive Therapy (MBCT) is a therapeutic approach which uses mindfulness. Cognitive basis of this approach is Teasdale's theory of interactive cognitive subsystems (Teasdale, 1993). In this theory, the relationship between cognitive and emotional processes is complicated and multidimensional. Teasdale refers to two kinds of beliefs: emotional beliefs (hot cognition) and rational beliefs (cold cognition). Teasdale's cognitive therapy is characterized by an emphasis on emotional beliefs (Teasdale, 1999). In this approach the participants are taught as soon as negative thoughts or feelings appeared, before answering to them, let them to remain intact in their mind. Additionally, this approach provides patterns for training decentralization skills and utilizes techniques in order to process information that makes thought-creating cycle's continuous (Segal, Williams, \& Teasdale, 2002). Mindfulness with the help of breathing and body, awareness of events, awareness of body, breathing, sound, and thoughts and accepting thoughts in a non-judgmentally manner result in changing of effective and emotional meanings and the individual learns that thoughts are simple rather than reflection of truth and these negative and worrying thoughts are not correct essentially. Mindfulness causes the individual to pay attention to his/her automatic activities and normal behaviors and obtains an increasing awareness and consciousness in his/her daily activities. This awareness of thoughts and feelings leads to change individual connection to those thoughts and feelings (Kabat-Zinn, 1990). In fact, mindfulness changes one's relationship to thoughts rather than changing the content of thought (Hayes, Strosahl, \& Wilson, 1999).

To date, two studies have investigated effectiveness of mindfulness based cognitive therapy on improvement of driving anger and aggression. Diebold (2003) adapted Kabat-Zinn's (1990) Mindfulness Based Stress Reduction (MBSR) program and Segal and colleagues' (2002) Mindfulness Based Cognitive Therapy (MBCT) program into a treatment protocol for college students in order to reduce driving anger. In this study, partici- pants were 12 graduated students ( 7 males and 5 females) that were divided into three groups containing 4 participants. Eleven participants showed a reduction in driving anger in follow-up. Twelve participants showed a reduction in driving anger frequency and 9 of 10 participants that reported an intense anger in baseline, showed a reduction in anger intensity. Reduction in driving anger and aggression were observed in 9 participants. After therapy, participants showed reduction in anger expression that continued commonly until follow-up. In follow-up, 12 participants showed a reduction in verbal anger expression and 11 participants showed an increase in adaptive/constructive expression. Also, a dissertation conducted by Polizzi (2008) examined the efficacy of MBCT in reducing driver anger among a sample of young adults. Support was found for the use of MBCT to reduce scores on the Driving Anger Scale, reduce the frequency of anger and aggressive behaviors reported on the driver logs, reduce scores on the State Anger Scale, and increase scores on Adaptive/Constructive Expression while driving.

Although the results of CBT and MBCT interventions are promising, there are inconsistencies and equivocal evidences for their effectiveness. In addition, no study, as yet, compared the effectiveness of CBT to MBCT in research literature; therefore, the aim of the current study is to compare the effectiveness of CBGT with MBCGT in the reduction of driving anger and aggression. The hypothesis of the research was MBCGT decreases of driving anger and aggression significantly more than CBGT.

\section{Method}

The present study is an experimental research with pretest, posttest and follow-up design. In this research, independent variable was group therapy factor with two levels: 1) mindfulness based cognitive therapy and 2) cognitive-behavioral therapy that were performed separately in the one of experimental groups during 6 weeks. Dependent variables in this study included: driving anger, aggressive expression of driving anger and adaptive/constructive expression of driving anger that their changes were measured in both groups before and after independent variable performing and also after 1 month follow-up.

\section{Participants}

The population of research included all male taxi drivers of Mashhad who were selected with accessible sampling and voluntarily in September 2011. After approval of taxi-driving organization and putting advertisement on the bulletin board of the organization in order to present information about holding therapeutic sessions for driving anger management, 20 drivers that had no thought disorder and drug abuse were selected by means of structural clinical interview (DSM-IV) and assigned in mindfulness based cognitive group therapy (10 drivers) and cognitive-behavioral group therapy (10 drivers) randomly. Age mean of mindfulness based cognitive group therapy and cognitive-behavioral group members were $46.70 \pm 11.97$ and $45.10 \pm$ 17.86, respectively. History of driving mean in mindfulness based cognitive group therapy and cognitive-behavioral group were $23.80 \pm 13.35$ and $19 \pm 10.57$ years, respectively. In mindfulness based cognitive group therapy, 10 percent of group members had elementary degree, 40 percent primary high school, 40 percent high school diploma and 10 percent associ- 
ate degree. In cognitive-behavioral group, 30 percent of group members had elementary education and 70 percent high school diploma.

\section{Instruments}

The study administered three instruments:

1) Driving Anger Scale, Short Form (DAS): The DAS contains 14 driving situations that are rated on a $1-5$ scale $(1=$ not at all, $5=$ very much) for amount of anger experienced if they occurred (Deffenbaccher et al., 1994). Prior to this main study, validity and reliability of Farsi version of DAS were examined in a pilot study carried out by researchers. All items of the DAS were translated into Farsi and back to English by three independent translators reaching the final version by consensus. One hundred taxi drivers ( 80 men, 20 women) completed DAS and Driving Log. The correlations between DAS and frequency and intensity of anger when driving (.65) and between DAS and frequency of aggressive and risky driving behaviors (.78) were regarded as indices of convergent validity. They were retested after one month. The results showed a significant test-retest reliability quotient (.76) for DAS. The Cronbach's $\alpha$ coefficient of this scale at baseline and at follow-up in the present study were .80 and .82 , respectively.

2) Driving Anger Expression Inventory (DAX): The 49 items of the DAX are rated on a 4-point scale $(1=$ almost never, $4=$ almost always), according to how the individual expresses his/her anger driving (Deffenbaccher et al., 2001; Deffenbaccher, Lynch, Oetting, \& Swaim, 2002b). The DAX breaks down into two general dimensions, a 34-item $(\alpha=.80)$ hostile/ aggressive expression and a 15 item $(\alpha=.90)$ adaptive/constructive expression, which share a small, native correlation $(r$ $=-.24)$. Hostile/aggressive expression correlates positively with roadway anger, aggression, and risky behavior, whereas adaptive/constructive expression tends to more strongly related to these variables than adaptive/constructive expression. All items of the DAX were translated into Farsi and back to English by three independent translators reaching the final version by consensus. The Cronbach's $\alpha$ coefficient of this scale at baseline and at follow-up in the present study were .82 and .86 , respectively.

3) Demographic Questionnaire: A demographic questionnaire was used to collect relevant background information about each participant. Participants were asked to report their age, education, and history of driving.

\section{Procedure}

The participants were assigned in two experimental groups randomly. The first experimental group (MBCT) began to perform with 10 members by a female therapist and a male assistant therapist. Group therapy included 6 sessions with the length of 120 minutes ( 2 hours) which was held in the conference hall of Homa Hotel of Mashhad in Iran. In this hall, the chairs were arranged roundly so that all members and therapist can see each other. In order to present educational and remedial matters and help to understand them, one board and one Projector device set were used.

During the first session, demographic questionnaire, Driving Anger Scale and Driving Anger Expression Inventory were distributed among group members at the beginning. Then, it was explained about group structure and aims, ground rules, concepts of mindfulness and automatic pilot. After initial summarizing, mindful raising exercise, revising and discussing it were dealt with within a period of 25 minutes. Then body scan was conducted and it was discussed. Pamphlets and homework were presented in the final 10 minutes of the first session.

In the second session, firstly, body scan was performed with the length of 20 minutes. Then, homework revising, discussing and answering to group members' questions, reading vignette of Levine and discuss it, answering to group members' questions and solving their problems, sitting meditation with the length range from 10 to 15 minutes, pleasant event calendar were dealt with and like the previous session, pamphlets and homework were presented.

During the third session, 5-minute hearing exercise, 30minute sitting meditation and review it, reviewing homework, 3-minute breathing space exercise, walking meditation, and review it, unpleasant event calendar and presenting pamphlets and homework were done.

In the fourth session, in addition to review homework, listening exercise, sitting meditation, 3-minute breathing space were done; also, driving anger and general anger were spoken about.

In the fifth session, in addition to review homework, sitting meditation and breathing space were conducted, the Roman poem "The Guest House" was read and it was spoken about problem-focused and emotion-focused coping strategies and tree in storm analogy.

Finally, in the sixth session, sitting meditation exercises, breathing space and meditation using mountain imagery were done; it was dealt with the relationship between mood and thoughts and to exercise alternative views and procedures that make changes continue and terminated with meditation of a stone. It should be noted that in the end of sixth session, driving anger and driving anger expression questionnaires were distributed among group members once again and a date was appointed for one month follow-up session with the consent of the members. During MBCGT sessions, in order to consistency and integrity of mind and body and more usefulness of mindfulness techniques, yoga training films were given to the group members.

In the second experimental group (CBT), selection and assignment of members, place and holding way of group sessions were the same as the first experimental group. The period of conducting intervention in this group was like that of the first experimental one, i.e. six weeks (each week one 2-hour session). Meanwhile this group, members had no contact with the first experimental group during therapy.

In the beginning of the first session, the participants were given demographic questionnaire, driving anger questionnaire and driving anger expression. In this session, ground rules regarding confidentiality and privacy, orientation of the class, introduction to interactions between thought, behavior, and physiology, sequence of A-B-C, saint and suitcase analogy were spoken about; at last, the group conducted guided imaginary relaxation exercise.

Second session, Homework review, review of previous session, most important aspects of cognitive theories of emotions, characteristics of automatic thoughts ,cognitive distortions, resistance to cognitive therapy, designing strategies for confronting these resistances and homework assignments were dealt with.

In the third session, in addition to Homework review, dis- 
cussion and questions, behavioral and emotional consequences of thoughts, schemas, relationship between schemas and automatic thoughts and recognizing schemas using vertical arrow method were raised.

The content of the fourth session included master list of beliefs, cognitive map, ranking subjective units of distress (SUD), objective analysis, utility analysis and consistency analysis.

In the fifth session, logical analysis, providing anger hierarchy, rehearsing the counters and perceptive change issues were posed. Finally in the sixth session, self-punishment methods and self-rewarding and maintance strategies were spoken about. In the end of the session, posttest questionnaires were completed by the group members and a date was appointed for one month follow-up session with the consent of the members. It should be noted that homework was presented to the group members in all sessions.

\section{Results}

The mean and standard deviation of driving anger, aggressive expression of driving anger and adaptive/constructive expression of driving anger scores in two groups in pretest, posttest and follow-up sessions was shown in Table 1. In order to compare two groups in age and history of driving and education variables, independent $t$ and nonparametric Mann-Whitney U test were used, respectively. The results showed that there was no significant difference between the two groups in age, history of driving variables and education $(p>.5)$. Thus, in inferential analysis for testing hypotheses, it was not necessary to insert these variables as covariate in statistical model.

In this study, pretest scores were recognized as confounder variables, therefore their effects on posttest and follow-up scores using covariance analysis were controlled. Taking into consideration that covariance analysis is included in parametric tests, at first defaults of distribution normalization and variances equality was examined. Kolmogorov-Smirnow Test was used for studying pretest of normalization assumption and results showed that scores have normal distribution in two groups. Also Leven's test was done in order to examine variances. Results showed that disparity of pretest scores of driving anger ( $\mathrm{F}$ $=.83, p=.37)$, driving anger adaptive/constructive expression $(\mathrm{F}=.004, p=.95)$ and driving anger aggressive expression $(\mathrm{F}$ $=.5, p=.48$ ) were the same in two groups. As a result, there was variances equality condition and taking into consideration that scores distribution is normal, there was no problem in using covariance analysis.

In order to compare the effectiveness of two groups in decreasing of anger driving, analysis of covariance test (ANCOVA) was used. Table 2 shows the results of analysis of covariance. After modifying driving anger scores of pretest stage using analysis of covariance test, there was a significant difference between MBCGT and CBGT in the driving anger scores of posttest stage $(\mathrm{F}=15.45, p=.000)$ and follow-up stage $(\mathrm{F}=7.45, p=.01)$. Comparing the means of two groups (Table 1) shows that in posttest stage, driving anger scores in MBCGT has been decreased more than CBGT significantly and this difference has been significant in follow-up stage, too. Impact rate of group therapy type on decrease of driving anger in posttest was .52 and follow-up .3. In fact, 52 percent of scores variance in two groups in posttest and 30 percent of scores variance in two groups in follow-up was due to group membership.

In order to compare the effectiveness of two groups in im-

Table 1.

Means and standard deviation for anger driving, aggressive expression, and adaptive/constructive expression of all participants.

\begin{tabular}{cccc}
\hline \multirow{2}{*}{ Variables } & Time & CBT Group & MBCT Group \\
\cline { 3 - 4 } & & M $^{*}\left(\mathrm{SD}^{* *}\right)$ & M (SD) \\
\hline \multirow{2}{*}{ Anger driving } & Pre & $41.80(4.39)$ & $34.80(5.27)$ \\
& Post & $35.60(6.02)$ & $28.70(3.74)$ \\
Aggressive expression & Fallow & $34.30(5.92)$ & $24.40(3.86)$ \\
& Pre & $52.40(7.13)$ & $55.20(5.30)$ \\
Adaptive/constructive expression & Post & $42.90(5.66)$ & $40.20(2.44)$ \\
& Fallow & $43.30(4.62)$ & $39.90(1.96)$ \\
& Pre & $38.60(7.80)$ & $39.70(7.57)$ \\
\end{tabular}

"Mean; ** Standard deviation.

Table 2.

Analysis of covariance to control for the effect size of pre test.

\begin{tabular}{ccccccc}
\hline Source & Variables & Sum of squares & Mean square & F & $p$ & Partial eta squared \\
\hline \multirow{2}{*}{ Pretest of anger driving } & Posttest of anger driving & 281.371 & 281.371 & 27.95 & .000 & .62 \\
& Follow-up of anger driving & 228.116 & 228.116 & 17.43 & .001 & .50 \\
\multirow{2}{*}{ Group } & Posttest of anger driving & 241.353 & 241.352 & 15.45 & .000 & .52 \\
& Follow-up of anger driving & 75.06 & 75.06 & 7.45 & .01 & .30 \\
\hline
\end{tabular}


proving of aggressive expression of driving anger and adaptive/constructive expression of driving anger, Multivariate analysis of covariance test (MANCOVA) was used (Table 3). After modifying aggressive expression and adaptive/constructive expression of driving anger scores of pretest stage, the results of MANCOVA showed a significant difference between MBCGT and CBGT in driving anger adaptive/constructive expression in posttest stage $\left(\mathrm{F}_{(1,18)}=17.90, p=.001, \eta^{2}=.52\right)$ and follow-up stage $\left(\mathrm{F}_{(1,18)}=20.73, p=.000, \eta^{2}=.56\right)$. Comparing the means of two groups (Table 1) shows that in posttest, driving anger adaptive/constructive expression scores in MBCGT has been increased more than CBGT significantly and this difference has been significant in follow-up too. Impact rate of group therapy type on driving anger adaptive/constructive expression improvement in posttest was .52 and follow-up .56, i.e., 52 percent of scores variance in two groups in posttest and 56 percent of scores variance in two groups in follow-up was due to group membership.

Also, the result of MANCOVA showed a significant difference between MBCGT and CBGT in driving anger aggressive expression in posttest $\left(\mathrm{F}_{(1,18)}=5.22, p=.03, \eta^{2}=.24\right)$ and follow-up $\left(\mathrm{F}_{(1,18)}=10.13, p=.006, \eta^{2}=.38\right)$. Comparing the means of two groups (Table 1) shows that in posttest, driving anger aggressive expression scores in MBCGT has been decreased more than CBGT significantly and this difference has been significant in follow-up too. Impact rate of group therapy type on driving anger aggressive expression improvement in posttest was .24 and follow-up .38 , i.e, 24 percent of scores variance in two groups in posttest and 38 percent of scores variance in two groups in follow-up was due to group mem- bership.

\section{Discussion}

The results of the present study showed that the effectiveness of mindfulness based cognitive group therapy in reduction of driving anger and aggression is more than cognitive-behavioral group therapy significantly. Although, any research has directly dealt with comparing the effectiveness of this two therapeutic approach in improving of driving anger and aggression so far, results of the present study can be explain regarding cognitive component of these approaches; Beck's theory is the cognitive basis of cognitive-behavioral therapy while mindfulness based cognitive therapy is based on Teasdale's interactive cognitive subsystems. According to Beck, cognition has a main role in psychopathology. He believes that other aspects such as emotional, behavioral and physiological ones are derived from this aspect (Ghasemzade, 2008), whereas mindfulness has primarily been holistic intervention that doesn't differentiate between body and mind basically (Rothwell, 2006). This model works with whole existence and personality of individual simultaneously and considers him/her as an integrated whole. Mindfulness method which is consistent with interactive cognitive subsystems works on physical and sensational effects and individual's thoughts, emotions and excitements simultaneously (Ataeee-Nakhaei, 2008). Traditional cognitive therapies change intellectual beliefs of individual only and manipulate emotional beliefs less than intellectual ones, while emphasis on emotional beliefs is included in Teasdale's cognitive therapy characteristics. Also, Beck (1975) believes that therapy should be begun

Table 3.

Multivariate analysis of covariance to control for the effect size of pre test.

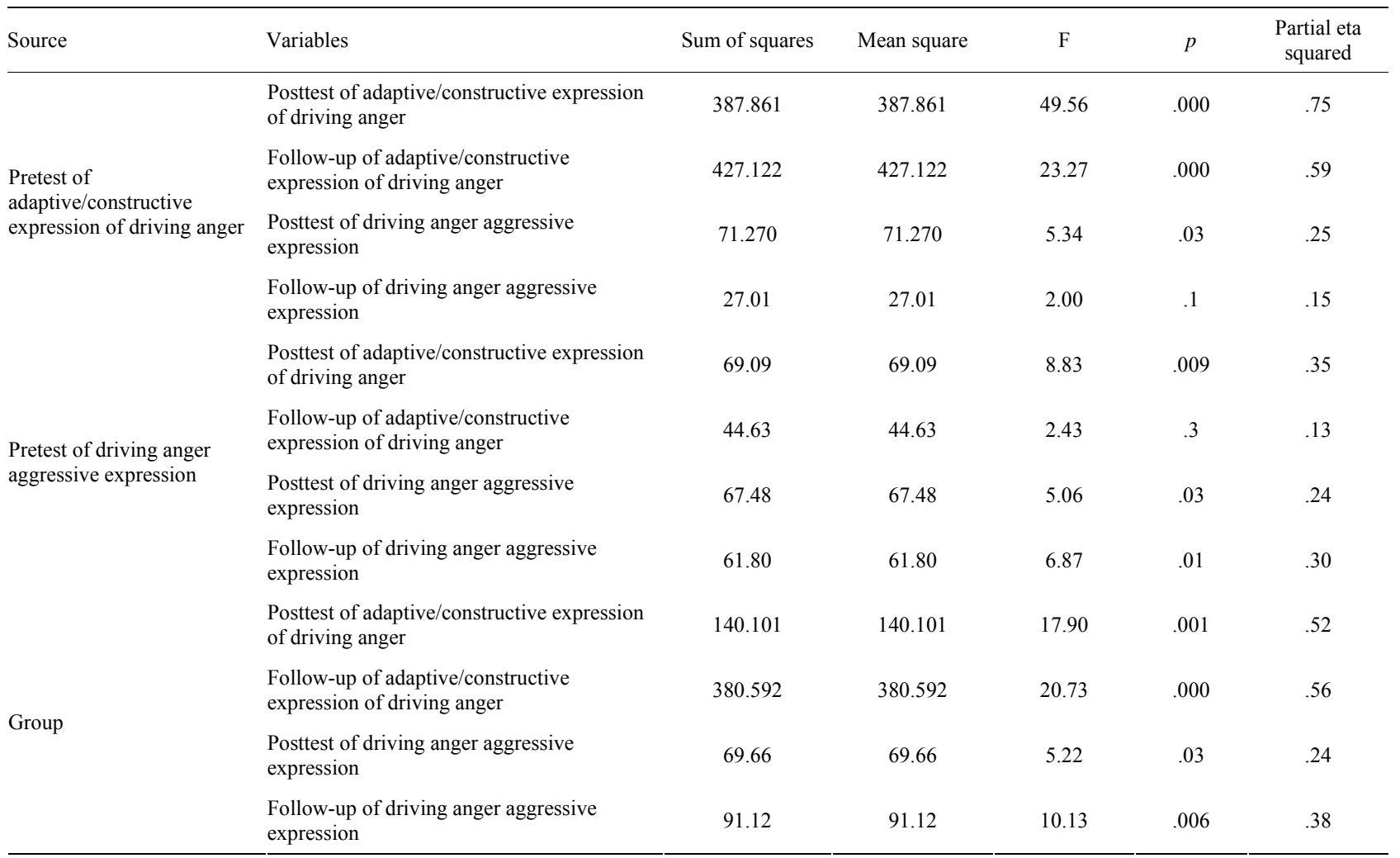


from automatic negative thoughts levels whereas Teasdale considers that work in the level of these core thoughts and believes of patients doesn't appear adequate for therapy. The relationship between cognitive processes and emotion in Teasdale's interactive cognitive subsystems is complicated and multidimensional. This new model aims to change schema not to make specific meanings invalid in patient's mind. Furthermore, mindfulness changes individual's connection with his/her thoughts rather than changing thoughts content (Hayes et al., 1999). The technique's goal is not to put up negative thoughts from mind but the goal is to prevent these thoughts strengthening. Mindfulness with the help of breathing and using body organs, awareness of events, awareness of body, breathing, voice and thoughts and to accept them without judgment about them leads to change specific sensational and emotional meanings and the individual learns that thoughts are simple rather than the reflection of truth and thoughts such as "I am a loser" or "I will not succeed" are essentially correct no longer. This method causes the individual to pay attention to his/her automatic and habitual behaviors and gains increasing awareness and mindfulness in him/her daily activities (Peterson \& Pbert, 2007). Cognitive change in mindfulness based cognitive therapy is made so that participants are taught whenever negative thoughts or feelings emerge in their mind, before responding to them skillfully let them remain intact in their mind. In addition, it provides patterns for training decentralization skills and utilizes techniques for information processing that make thinking-creation cycles permanent (Segal et al., 2002), while cognitive change in cognitive-behavioral approach is made so that the individuals are taught more logical thinking skills and they learn that oppose their negative thoughts consciously (Free, 1999).

In addition, mindfulness based cognitive therapy uses techniques such as body scan, sitting meditation, breathing exercise and so on that help promotion of relaxation response (Shapiro, Schwartz, \& Bonner, 1998, improve regulation of attention and concentration (Diebold, 2003). Indeed, mindfulness provides techniques for coping with anger (Berslin, Zack, \& McMain, 2002), while less behavioral and relaxation techniques have been used in cognitive-behavioral approach and emphasized mostly on recognition of automatic negative thoughts, logical errors and main negative beliefs.

With regard to the results of this research, it can be concluded that mindfulness based cognitive group therapy can more curative impacts on driving anger and aggression in comparison to cognitive behavioral group therapy and it is better to prefer this kind of therapy in intervention measures in order to improve driving anger and aggression.

Limitations and Suggestions: One of the limitations of present study was using between-group design; Between-group research does not allow researchers to understand the characteristics of participants for whom the treatment was or was not effective. Other limitations included unclear role and mechanism of mindfulness in driving anger and aggression therapy, performing research on accessible and small sample, short-term follow-up stage, and using self-report instruments. Although the used instruments had acceptable reliability and validity, validity of self-report tools depends on subjects' truthfulness and accuracy in answering to test matters totally. Since the sample was male taxi drivers, the results can only be applied to the male population.

For future research, it is suggested that the present study to be performed in the single-subject experimental design frame- work in order to better understanding characteristics of participants for whom the treatment was or was not effective. A longer follow-up phase would provide evidence on the persistence of the changes. Also, in order to increase accuracy of evaluation of anger and aggression can be used various methods and tools of measurement. It is recommended that in addition to self-report questionnaires, clinical interview with participant and entourage, clinical examination, and direct observation of subjects in natural setting to be used for measuring anger and aggression in different stages (pretest, posttest and follow-up). Furthermore, it is recommended that effectiveness of integrating mindfulness based cognitive therapy and cognitive-behavioral therapy on decreasing driving anger and aggression to be evaluated in future research.

\section{REFERENCES}

American Atomobile Association Foundation for Traffic Safty (1997). Aggressive driving: Three studies. Washington DC: Author.

Ataee-e-Nakhaei, A. (2008). The effect of mindfulness-based group therapy with study skills training on test anxiety and trait anxiety. Postgraduate Dissertation, Mashhad: Ferdowsi University of Mashhad, Unpublished.

Berslin, F. C., Zack, M., \& McMain, S. (2002). An information-processing analysis of mindfulness: Implications for prevention in treatment of substance abuse. Clinical Psychology: Science and Practice, 9, 275-299. doi:10.1093/clipsy.9.3.275

Bishop, S. R. (2002). What do we really know about mindfulness-based stress reduction? Psychosomatic Medicine, 64, 71-83.

Borders, A., Earleywine, M., \& Jajodia. A. (2010). Could mindfulness anger, hostility, and aggression by decreasing rumination? Aggressive Behavior, 36, 28-44. doi:10.1002/ab.20327

Brown, K. W., \& Ryan, R. M. (2003). The benefits of being present: Mindfulness and its role in psychological well-being. Journal of Personality and Social Psychology, 84, 822-848. doi: $10.1037 / 0022-3514.84 .4 .822$

Corey, G. (2009). Theory and practice of counseling and psychotherapy. USA: Thomson Brooks/Cole Press.

Deffenbacher, J. L., Filetti, L. B., Lynch, R. S., Dahlen, E. R., \& Oeting, E. R. (2002a). Cognitive-bahavioral treatment of high anger drivers. Behavior Research and Therapy, 40, 895-910. doi:10.1016/S0005-7967(01)00067-5

Deffenbacher, J. L., Huff, M. E., Lynch, R. S., Oetting, E. R., \& Salvatore, N. F. (2000). Characteristics and treatment of high anger drivers. Journal of Counseling Psychology, 47, 5-17. doi:10.1037/0022-0167.47.1.5

Deffenbacher, J. L., Lynch, R. S., Deffenbacher, D. M., \& Oetting, E. R. (2001). Further evidence of reliability and validity for the driving anger expression inventory. Psychological Reports, 89, 535-540.

Deffenbacher, J. L., Lynch, R. S., Oetting, E. R., \& Swaim, R. C. (2002b). The driving anger expression inventory: A measure of how people express their anger on the road. Behavior Research and Therapy, 40, 717-737. doi:10.1016/S0005-7967(01)00063-8

Deffenbacher, J. L., Oetting, E. R., \& Lynch, R. S. (1994). Development of a driving anger scale. Psychological Reports, 74, 83-91. doi:10.2466/pr0.1994.74.1.83

Diebold, J. (2003). Mindfulness in the machine: A mindfulness-based cognitive therapy for the reduction of driving anger. Ph.D. Dissertation. New York: Hofstra University, Unpublished

Ellison, P. A., Govern, J. M., Petri, H. M., \& Figler, M. H. (1995). Anonymity and aggressive driving behavior: A field study. Journal of Social Behavior and Personality, 10, 265-272.

Ellison-Potter, P., Bell, P., \& Deffenbacher, J. L. (2001). The effects of trait driving anger, anonymity, and aggressive stimuli on aggressive driving behavior. Journal of Applied Social Psychology, 31, 431-443. doi:10.1111/j.1559-1816.2001.tb00204.x

Free, M. L. (1999). Cognitive therapy in groups: Guide lines and resources for practice. New York: John Wiley Press. 
Galovski, T. E., Blanchard, E. B., \& Veazey, C. (2002). Intermittent explosive disorder and other psychiatric comorbidity among courtreferred and self-referred aggressive disorders. Behavior Research and Therapy, 40, 641-651. doi:10.1016/S0005-7967(01)00030-4

Galovski, T. E., Blanchard, E. B., Malta, L. S., \& Freidenberg, B. M. (2003). The psychophysiology of aggressive drivers: Comparison to non-aggressive drivers and pr-to post-treatment change following a cognitive-behavioral treatment. Behavior Research and Therapy, 41, 1055-1067. doi:10.1016/S0005-7967(02)00242-5

Ghasemzade, H. (2008). Cognition and affect (clinical and social aspects). Tehran: Farhangan Press.

Hauber, A. R. (1980). The social psychology of driving behavior and traffic environment: Research on aggressive behavior in traffic. International Review of Applied Psychology, 29, 461-474. doi:10.1111/j.1464-0597.1980.tb01106.x

Hayes, S. C., Strosahl, K. D., \& Wilson, K. G. (1999). Acceptance and commitment theray: An experimental approach to behavior change. New York: The Guilford Press.

Hennssy, D. A., \& Wiesenthal, D. L. (1999). Traffic congestion, driver sress, and driver aggression. Aggressive Behavior, 25, 409-423. doi:10.1002/(SICI)1098-2337(1999)25:6<409::AID-AB2>3.0.CO;2-0

Heppner, L. W., kernis, M. H., Lakey, C. E., Campbell, W. K., Goldman, B. M., Davis, P. J., \& Cascio, E. V. (2008). Mindfulness as a means of reducing aggressive behavior: Dispositional and situational evidence. Aggressive Behavior, 34, 486-496. doi:10.1002/ab.20258

Kabat-Zinn, J. (1990). Full catastrophe living using the wisdom of your body and mind to face stress, pain, and illness. New York: Bantam Doubleday Dell Publishing Group, Press.

Malta, L. S., Blanchard, E. B., Freidenbreg, B. M., Galovski, T. E., Karl, A., \& Holzapfel, S. R. (2001). Psychological reactivity of aggressive drivers: An exploratory study. Applied Psychophysiology and Biofeedback, 26, 95-116. doi:10.1023/A:1011373105966

Murray, C., \& Lopez, A. (1997). Alternative projections of mortality and disability by cause 1990-2020: Global burden of disease study. Lancet, 349, 1498-1504. doi:10.1016/S0140-6736(96)07492-2

National Highway Traffic Safety Administration (1999). Traffic safety facts 1999: Speeding. Washington DC: Author.

Novaco, R. W., Stokols, D., \& Milanesi, L. (1990). Objective and subjective dimensions of travel impedance as determinants of commuting stress. American Journal of Community Psychology, 18, 231-257. doi:10.1007/BF00931303

Parker, D., Lajunen, T., \& Stardling, S. (1998). Attitudinal predictors of aggressive driving violation. Transportation Research Part F, 1, 1124. doi:10.1016/S1369-8478(98)00002-3

Parkinson, B. (2001). Anger on and off the road. British Journal of Psychology, 92, 507-526. doi:10.1348/000712601162310

Peterson, L. G., \& Pbert, L. (1992). Effectiveness of a meditation-based stress reduction program in the treatment of anxiety disorders. Ame- rican Journal Psychiatry, 149, 936-943.

Phares, E. J. (1992). Clinical psychology: Concepts, methods, \& profession. Belmont, CA: Thomson Brooks/Cole Press.

Pinto, D. (2001). Driving anger, articulated cognitive distortions, cognitive deficiencies and aggression. Unpublished Doctoral Dissertation. New York: Hofstra University.

Polizzi, T. N. (2007). An examination of mindfulness-based cognitive therapy for anger drivers. Unpublished Doctoral Dissertation, New York: Hofstra University.

Rasmussen, C., Knapp, T. J., \& Garner, L. (2000). Driving-induced stress in urban college students. Perceptual and Motor Skills, 90, 437-443. doi: 10.2466/pms.2000.90.2.437

Richards, T. L., Deffenbacher, J. L., Filetti, L. B., Lynch, R. S., \& Kogan, L. R. (2001). Short- and long-term effects of intervention for driving anger reduction. Paper Presented at 109th Annual Convention of the American Psychological Association, San Francisco, CA.

Rimm, D. C., DeGroot, J. C., Boord, P., Heiman, J., \& Dillow, P. V. (1971). Systematic desensitization of an anger response. Behavior Research and Therapy, 9, 273-280. doi:10.1016/0005-7967(71)90013-1

Rothwell, N. (2006). The different faces of mindfulness. Journal of Rational-Emotive \& Cognitive-Behavior Therapy, 24, 79-86. doi:10.1007/s10942-006-0023-4

Segal, Z. V., Williams, J. M., \& Teasdale, J. D. (2002). Mindfulnessbased cognitive for therapy depression. New York, NY: The Gilford Press.

Shapiro, S. L., Schwartz, G. E., \& Bonner, G. (1998). Effects of mindfulness-based stress reduction in medical and premedical students. Journal Behavioral Medicine, 21, 581-599. doi:10.1023/A:1018700829825

Teasdale, J. D. (1993). Emotion and two kinds of meaning: Cognitive theory and applied cognitive science. Behavior Research and Therapy, 4, 339-354. doi:10.1016/0005-7967(93)90092-9

Teasdale, J. D. (1999). Metacognition, mindfulness and the modification of mood disorders. Clinical Psychology \& Psychotherapy, 6, $146-155$.

doi:10.1002/(SICI)1099-0879(199905)6:2<146::AID-CPP195>3.0.C $\underline{\mathrm{O} ; 2-\mathrm{E}}$

Underwood, G., Chapman, P., Wright, S., \& Crandall, D. (1999). Anger while driving. Transportation Research Part F, 2, 55-68. doi:10.1016/S1369-8478(99)00006-6

Vandervoort, D. J., Ragland, D. R., \& Syme, S. L. (1996). Expressed and suppressed anger and health problems among transit workers. Current Psychology: Developmental, Learning, Personality, and Social, 15, 179-193. doi:10.1007/BF02686950

Wright, S., Andrew, D., \& Howells, K. (2009). Mindfulness and treatment of anger problems. Aggression and Violent Behavior, 14, 396401. doi:10.1016/j.avb.2009.06.008 